\title{
TS \\ INTELLIGENT CONTROL STRATEGY TO MITIGATE THE HARMONIC DISTORTION IN WIND ENERGY SYSTEM
}

\author{
Garima Kunwar Sarangdevot ${ }^{1}$, Bhumika shrimali ${ }^{2}$, R.R. Joshi ${ }^{3}$ \\ E-Mail Id: garima2471994@gmail.com \\ ${ }^{1,2}$ M. Tech Student, Department of Electrical Engineering, CTAE, Udaipur, Rajasthan, India \\ ${ }^{3}$ Professor, Department of Electrical Engineering, CTAE, Udaipur, Rajasthan, India
}

Abstract- Wind energy technologies are improving even faster than other renewable resources in the 21 st century, such as solar, geothermal, etc. In this article, the conventional converter is replaced by a multilevel converter. This simple scheme introduces a low frequency harmonic distortion substance of high intensity into the PMSG and therefore increases the total loses in it. The fuzzy logic is often used as a machine side converter control technique to maintain the constant DC voltage provided to GSC without any additional DC-DC converter. The initially designed Based Load Side Converter (LSC) has been used to minimize harmonics and professional and nonordinately deliver the reactive power to the load. The feasibility of the proposed system model and integrated control strategy are verified using MATLAB/Simulink simulations.

Keywords: Permanent magnet synchronous generator (PMSG), Fuzzy logic control, Total harmonics distortion.

\section{INTRODUCTION}

Wind Energy is the most important renewable energy source used for the isolated operation of the power system generation as well as grid-connected applications. In low-power wind energy systems, permanent magnet synchronous generators (PMSG) with variable speed operation on a wind energy conversion system (WECS) will be used more extensively. The Wind Turbine Generator (WTG) performs in the variable speed variable frequency mode in order to achieve optimum wind energy extraction at low voltage variable pitch WECS[1-3].

In order to evaluate the multiple harmonic mitigation approaches, the established wind turbine model would be used in this work. The standard way to accomplish a grid-connected PMSG WECS with variable speed would be to use two conversion processes like this instead of the complex logic theory to get MPPT on PMSG WECS. The Permanent Magnet Synchronous Generator (PMSG) has significant wind turbine economic advantages, whereas variable speed operations are implemented in numerous technologies [4,5]. The System Side Converter controls the gird-side reactive power compensation and filtering of non-linear load harmonics [6-9].

In order to achieve fast dynamic response, the fuzzy interference technique is used, no overshoot is obtained and settling time is reduced to maintain the constant DC voltage [10]. In PMSG, the fuzzy based PI controller is configured up to improve the dynamic response and mitigate the DC link ripple connected between converters[1011]. The integrated Fuzzy model is used in this contribution of work to control the machine side converter to provide constant DC interface voltage without additional boost converter.

\section{WIND POWER CONCERSION SYSTEM}

The WECS considered in this work consists of a PMSG driven by a fixed pitch wind turbine; an AC-DC energy conversion stage implemented using three different approaches and a VS-CCI.

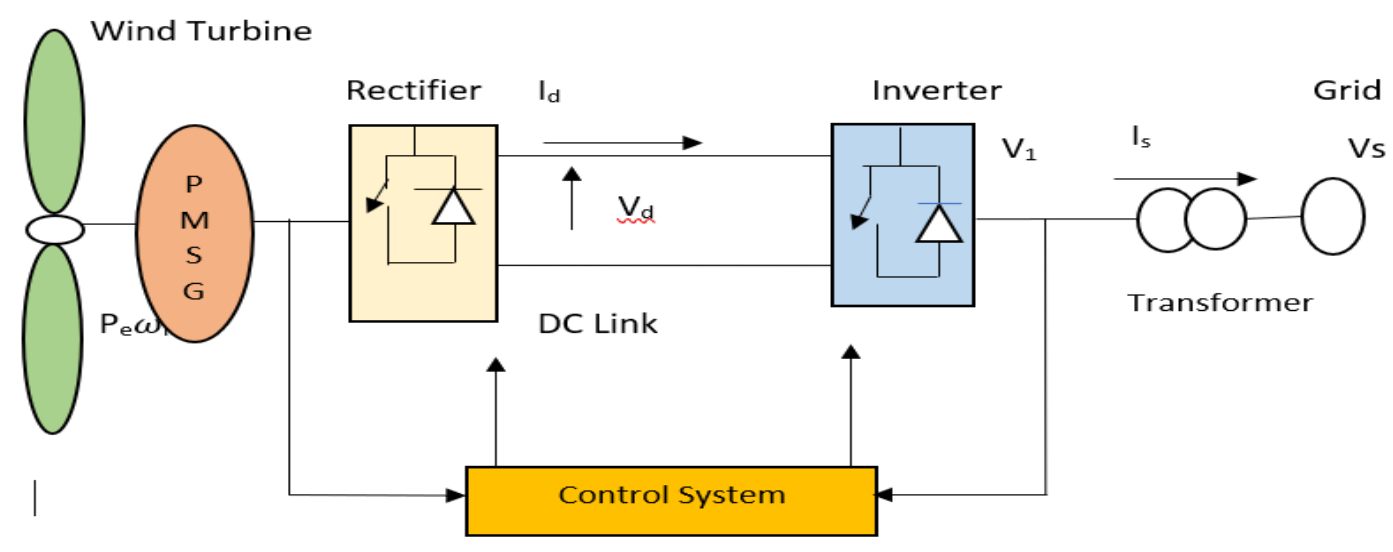

Fig. 2.1 Speed Wind Power Conversion System

A simplified variable speed wind power conversion system is sketched in Fig. 2.1 Where the variable speed wind turbine and generator are connected to the grid through aldolic type power electronic interface. Two selfcommutated PWM converters are employed at both machine and grid sides, which allows the dynamic control of the generator torque with vector control techniques. That means that the power coming from the generator and rectifier has to be immediately transferred to the ac system through the line side power converter.

DOI Number: https://doi.org/10.30780/IJTRS.V05.I12.001

pg. 1

wWw.ijtrs.com

WWw.ijtrs.org 


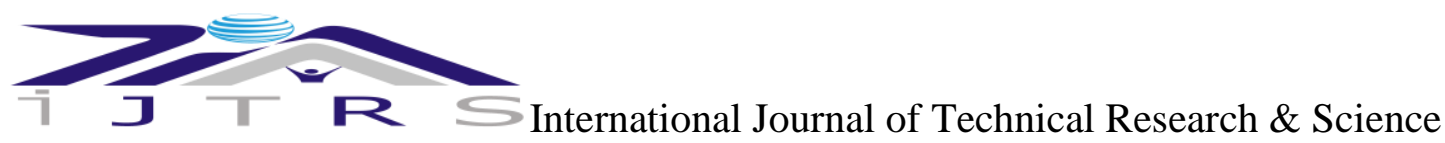

\section{MODELING OF PERMANENT MAGNET SYNCHRONOUS GENERATOR}

The power control of the PMSG is controlled by the orientation of the stator flux in the reference of synchronous rotation directed along the axis d. With that strategy, the active and reactive powers of the stator are decoupled [8]. The dynamic model of a PMSG in the dq reference frame can be represented by equations (1), (2) and (3) [8].

$V_{S d}=R_{M} i_{S}+\mathrm{L}_{\mathrm{sd}} \frac{d i_{5 d}}{d t}-\omega_{\mathrm{r}} \mathrm{L}_{\mathrm{sq}} \mathrm{i}_{\mathrm{sq}}$

$V_{S d}=R_{M} i_{S}+\mathrm{L}_{\mathrm{sd}} \frac{d i_{5 d}}{d t}+\omega_{2} L_{s q}-\omega_{\mathrm{r}} \mathrm{L}_{\mathrm{sq}} \mathrm{i}_{\mathrm{sq}}-\omega_{\mathrm{r}} \lambda_{\mathrm{m}}$

Where $V_{S d}$ and $\mathrm{V}_{\mathrm{sq}}$ are the stator voltage components, $\mathrm{R}_{\mathrm{m}}$ is the machine resistance, $\mathrm{L}_{\mathrm{sd}}$ and $\mathrm{L}_{\mathrm{aq}}$ are the stator inductances components, in a round rotor machine $\left(\mathrm{L}_{\mathrm{sd}}=\mathrm{L}_{\mathrm{sq}}\right), \mathrm{i}_{\mathrm{sd}}$ and $\mathrm{i}_{\mathrm{sq}}$ are the stator current components, $\omega_{\mathrm{r}}$ is generator speed and $\lambda_{\mathrm{m}}$ is magnetic flux. The electromagnetic torque in the rotor can written as:

$\bar{T}_{e}=\left(\frac{3}{2}\right)\left(\frac{P}{2}\right)\left[\left(\mathrm{L}_{\mathrm{sd}}-\mathrm{L}_{\mathrm{sq}}\right)\right] \mathrm{i}_{\mathrm{sq}} \mathrm{i}_{\mathrm{sd}}+\lambda_{\mathrm{m}} \mathrm{i}_{\mathrm{sq}}$

Where is the electromagnetic torque and is the number of poles. For the control of the generator, two new control variables are introduced from (1) and (2):

$\mathrm{u}_{\mathrm{d}}=\mathrm{V}_{\mathrm{sd}}+\omega_{\mathrm{r}} \mathrm{L}_{\mathrm{sq}} \mathrm{i}_{\mathrm{sq}}$

$\mathrm{u}_{\mathrm{q}}=\mathrm{V}_{\mathrm{sd}}-\omega_{\mathrm{r}} \mathrm{L}_{\mathrm{sq}} \mathrm{i}_{\mathrm{sq}}-\omega_{\mathrm{r}} \lambda_{\mathrm{m}}$

For stator current components regulation, (1) and (2) are rewrite to represent two decoupled, first-order, singleinput single-output (SISO):

$L_{S d} \frac{d i s}{d t}+\mathrm{R}_{\mathrm{M}} \mathrm{i}_{\mathrm{sd}}=\mathrm{u}_{\mathrm{d}}$
$L_{S q} \frac{d i s}{d t}+\mathrm{R}_{\mathrm{M}} \mathrm{i}_{\mathrm{sq}}=\mathrm{u}_{\mathrm{q}}$

Equations (6) and (7) regulate $i_{s d}$ and $i_{s q}$ for their references $i^{*}{ }_{s d}$ and $i^{*}$ sq through the scheme shown in the Fig. 2.1 .

\section{PROPOSED FUZZY WIND SPEED ESTIMATOR}

Input-output mapping problem can be solved in many ways such as using fuzzy system, linear system, expert systems. Before defining the fuzzy rules, we divide the wind speed range into 5 regions labelled with very low, low, average, high, and very high; the generator rotor speed into 3 regions labelled with low, medium, and high; the measured generator power into 5 regions labelled with zero, low, medium, high, and very high. Let Pg denote the measured generator power, $\mathrm{v}$ the wind speed, and wg the generator rotor speed. The fuzzy rules corresponding to the certain points on the power curve surface as shown in Figure 5 are defined as follows:

- Rule \#1: if wg is high and Pg is zero then $\mathrm{v}$ is very low

- Rule \#2: if wg is high and Pg is low then $v$ is low

- Rule \#3: if wg is high and $\mathrm{Pg}$ is medium then $\mathrm{v}$ is average

- Rule \#4: if wg is high and Pg is high then $\mathrm{v}$ is high

- Rule \#5: if wg is high and Pg is very high then $v$ is very high

- Rule \#6: if wg is medium and Pg is zero then v is very low

- Rule \#7: if wg is medium and Pg is low then v is low

- Rule \#8: if wg is medium and Pg is medium then $v$ is average

- Rule \#9: if wg is low and Pg is zero then $\mathrm{v}$ is very low.

\section{PMSG BASED WIND ENERGY CONVERSION SYSTEM MODEL}

PMSG based wind energy conversion system and control strategy discussed, the simulation results show test results on the proposed WECS, with continuous power supply, has been developed and verified in MATLAB/Simulink software using sim-power system block-set for real-time supervisory.

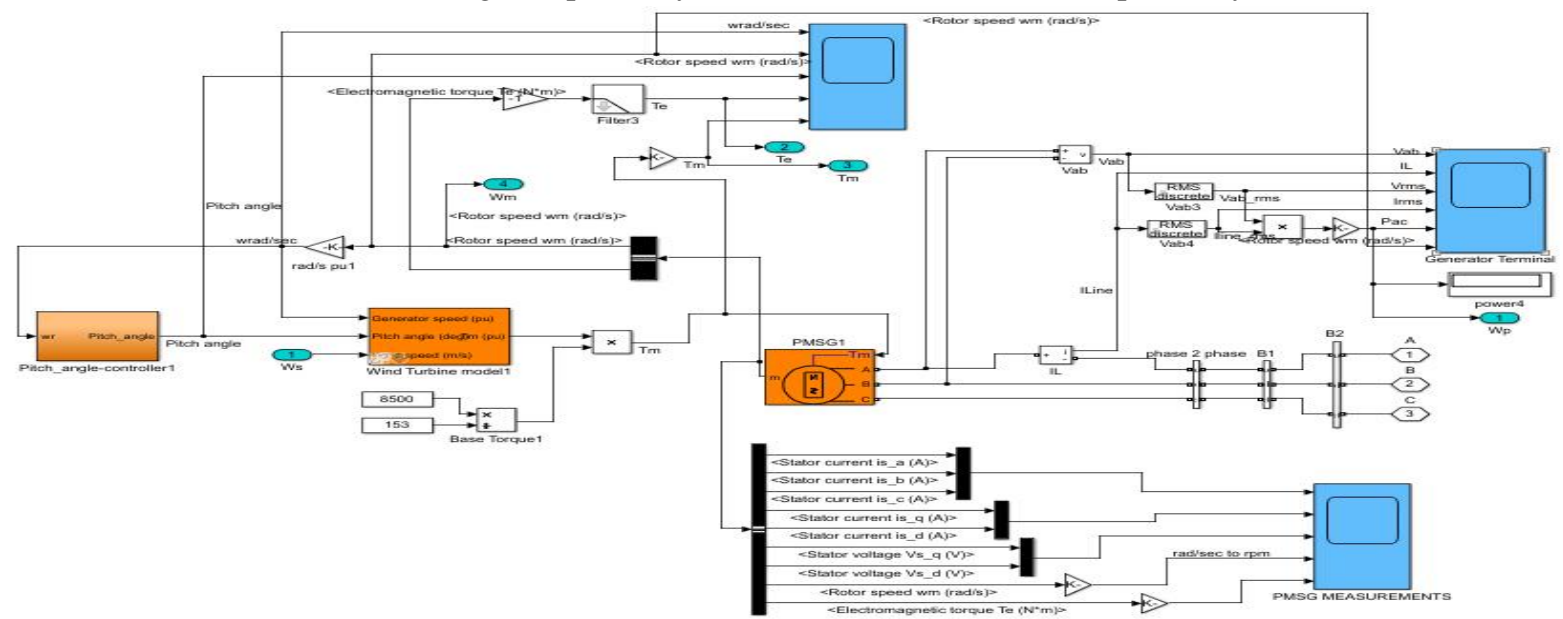

Fig. 5.1 PMSG Based Wind Energy Conversion System Model

DOI Number: https://doi.org/10.30780/IJTRS.V05.I12.001

pg. 2

wWw.ijtrs.com

wWw.ijtrs.org 


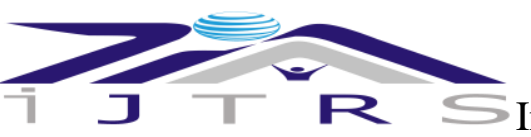

Developed PMSG based wind energy conversion system were observed at different input wind speed like linear increase, linear decrease, step change, successive increases and decreases and harmonic analysis at load side. Performance analysis of developed PMSG based wind energy conversion system and control strategy discussed at different input wind speed. The simulation results validate the reliability and stability of the modelled system.

\section{RESULTS FOR PMSG BASED WECS}

DC output from the DC-DC converter is given to DC link capacitors whose main purpose is to maintain the DC voltage at the input of the invertchanged er. Observations taken when speed change by steps like $12 \mathrm{~m} / \mathrm{s}-10 \mathrm{~m} / \mathrm{s}-$ $8 \mathrm{~m} / \mathrm{s}-6 \mathrm{~m} / \mathrm{s}$ and Fig. 3 shows the various waveforms of (a) multilevel inverter output voltage, (b) multilevel inverter output current, (c) multilevel inverter phase voltage and (d) multilevel inverter duty ratio. We can see in Fig. 6.1 multilevel inverter output current is $45 \mathrm{~A}$ and multilevel inverter output voltage is $500 \mathrm{~V}$.
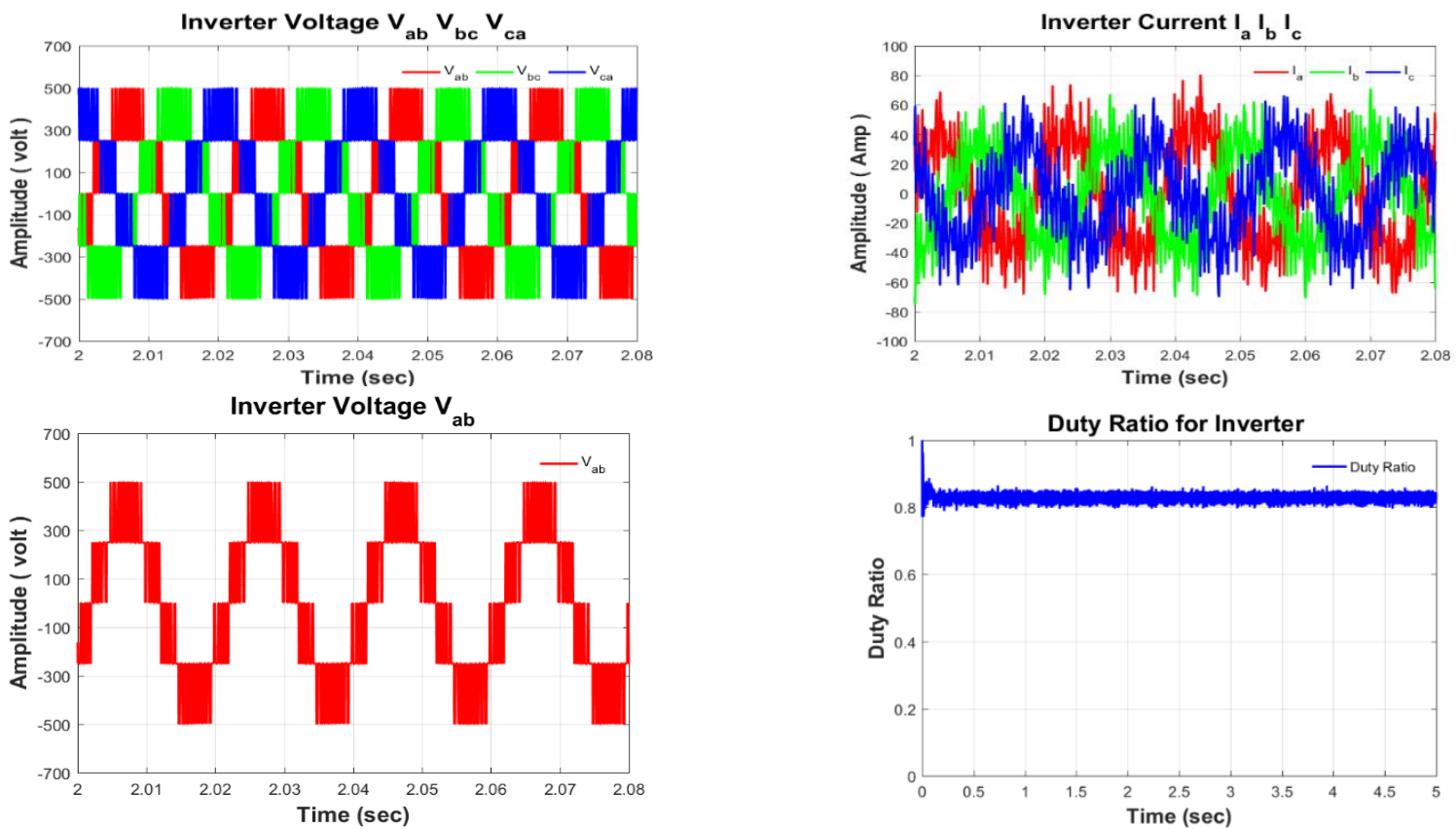

Fig. 6.1 Simulation Results for PMSG based WECS at Multilevel Inverter during Wind Speed Change from $12 \mathrm{~m} / \mathrm{s}$ to $10 \mathrm{~m} / \mathrm{s}$ to $8 \mathrm{~m} / \mathrm{s}$ to $6 \mathrm{~m} / \mathrm{s}$ : (a) Inverter Phase to Phase Voltage, (b) Inverter Phase Current, (c) Inverter Phase to Phase Voltage (d) Duty Ration of Inverter

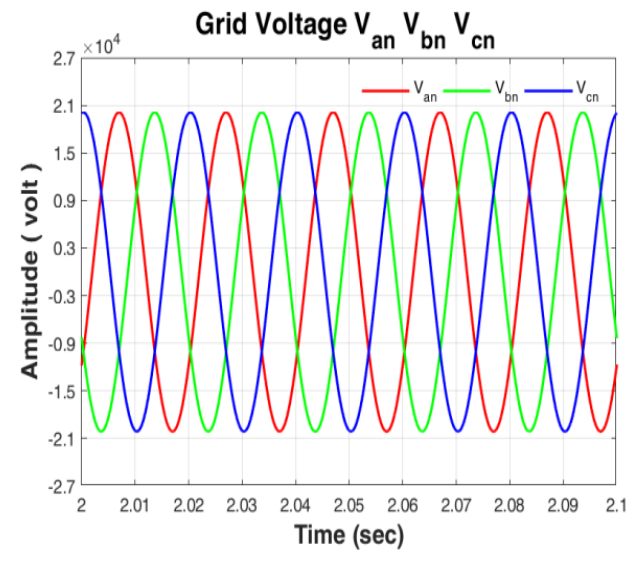

(a)

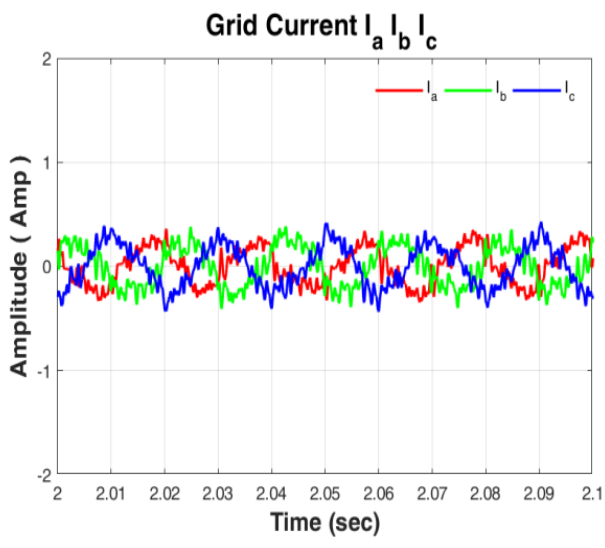

(b)

Fig. 6.2 Simulation results for PMSG based WECS at grid during wind speed change from $6 \mathrm{~m} / \mathrm{s}$ to $8 \mathrm{~m} / \mathrm{s}$ to $10 \mathrm{~m} / \mathrm{s}$ to $12 \mathrm{~m} / \mathrm{s}$ : (a) grid voltage, (b) grid current

Fig. 6.2 (a) shows the grid side phase voltages $V_{a n} V_{b n} V_{c n}$. Grid voltage is maintaining at $20 \mathrm{kV}$ and $50 \mathrm{~Hz}$ and Fig. 6.2 (b) shows the grid current $I_{a} I_{b} I_{c}$ is 0.2 p.u.

From the load current and voltage harmonic spectrum of Fig. 6.3(a, b), it can be seen that total harmonic distortion (THD) of load output current is $3.84 \%$, load output voltage is $4.06 \%$, which is less than $5 \%$ and it is in assent with the admissible limits of IEEE 1547, IEEE-519 and IEC 61727 standards and thus satisfies the general models and along these lines satisfies the general standards of produced power in terms voltage and current inside 5\% THD. Low THD is due to the use of because of space vector pulse width modulation (SVPWM) switching for the converter.

DOI Number: https://doi.org/10.30780/IJTRS.V05.I12.001

pg. 3

www.ijtrs.com

www.ijtrs.org 


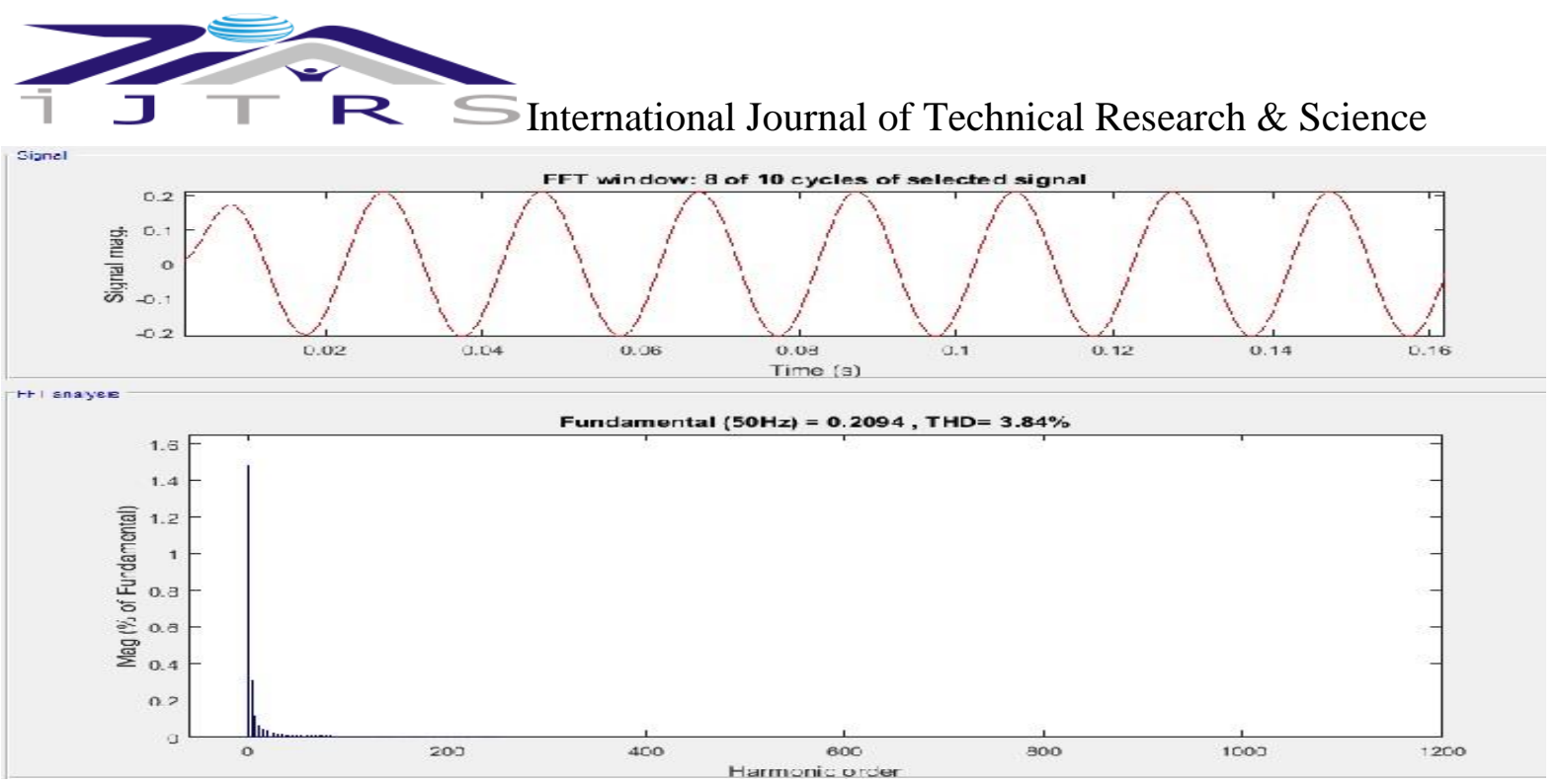

Fig. 6.3(a) Harmonic Spectrum of Output Load Current

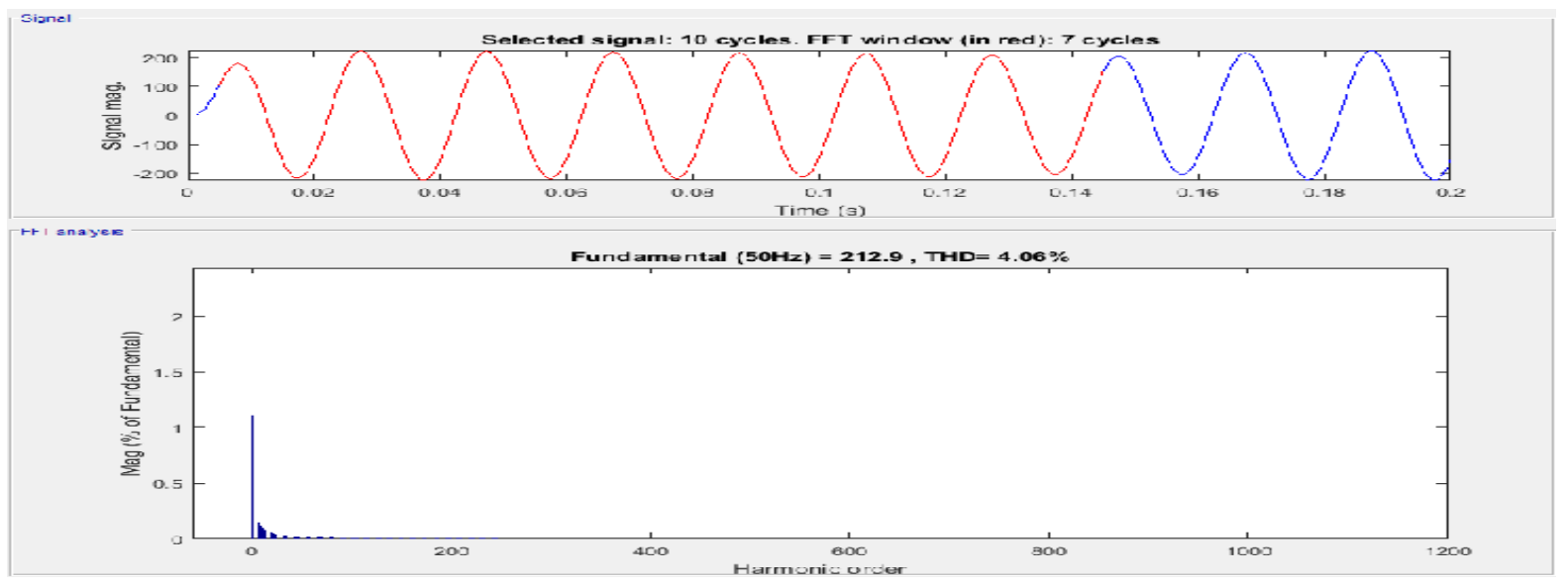

Fig. 6.3(b) Simulation Response of Harmonic Spectrum of Current and Voltage

\section{CONCLUSION}

The purpose of this paper is to investigate a wind power system with PMSG with multilevel inverter under various wind condition. The power delivered to the grid and dc-link voltage are well maintained with varying wind speed. The Wind Energy Conversion System, with wind turbine driven Permanent Magnet synchronous Generator (PMSG) is simulated using MATLAB. For various input wind velocities this system is analyzed and harmonic current and voltage with low-THD of $3.84 \%$ as per IEEE standards with the help of modified fuzzy logic controller.

\section{REFERENCES}

[1] H. Polinder, "Overview of and trends in wind turbine generator systems," in Proc. IEEE Power Eng. Soc. General Meeting, Jul. 2011.

[2] L. Wang and D. N. Truong, "Stability Enhancement of a Power System with a PMSG Based and a DFIGBased Offshore Wind Farm Using a SVC With an Adaptive-Network-Based Fuzzy Inference System", IEEE Transactions on Industrial Electronics, Vol. 60, No.7, pp. 27992807, 2013.

[3] Bisht, M. S.2014. Fuzzy based intelligent frequency control strategy in standalone hybrid ac microgrid. In: proceeding of IEEE Conference on Control Applications held at Juan Les Antibes, France October 8-10, 2014, pp. 873-878.

[4] Li, T., \& Ji, Z. C.2011. Intelligent inverse control to maximum power point tracking control strategy of wind energy conversion system. In: proceeding of IEEE Conference on Chinese Control and Decision held at Mianyang, China May 23-25, 2011, pp. 970-974.

[5] Bradt, M., Badrzadeh, B., Camm, E., Mueller, D., Schoene, J., Siebert, T. and Walling, R.2012. Harmonics and resonance issues in wind power plants. In: proceeding of IEEE Conference on PES T\&D held at Orlando, FL, USA May 7-10, 2012, pp. 1-8.

[6] Bellarbi, S., Koussa, D. S., and Rennane, A. 2015. Power control of a wind energy conversion system. In: proceeding of IEEE Conference on The Sixth International Renewable Energy Congress held at Sousse, Tunisia March 24-26, 2015, pp. 1-4. 


\section{7 $\longrightarrow$ \& International Journal of Technical Research \& Science}

[7] Kanathipan, K., and Lam, J. 2017. A new modified maximum power extraction technique for wind and hybrid renewable energy systems. In: proceeding of IEEE Conference on Electrical Power and Energy held at Saskatoon, SK, Canada October22-25 2017, pp. 1-6.

[8] Varma, S. D. K., and Bhavani, N. V. A. 2016. Power quality improvement in standalone battery integrated wind energy system. In: proceeding of IEEE Conference on International Conference on Signal Processing, Communication, Power and Embedded System held at Paralakhemundi, India October3-5, 2016, pp. 642647.

[9] Naba, A. 2014. Fuzzy logic principles for wind speed estimation in wind energy conversion systems In: proceeding of IEEE 6th International Conference on Information Technology and Electrical Engineering (ICITEE) held at Yogyakarta, Indonesia October 7-8, 2014, pp. 1-4.

[10] Ozcelik, M. A. 2017. The improve of energy efficiency on grid-based wind power systems. In: proceeding of International Conference on Smart Energy Grid Engineering held at Oshawa, ON, Canada 14-17, Aug. 2017, pp. 177-181.

[11] Zubova, N. V., and Achitaev, A. A. 2018. Application of Neuro-Fuzzy Control Systems for Increasing the Energy Efficiency of Wind Turbines. In: proceeding of International Scientific-Technical Conference on Actual Problems of Electronics Instrument Engineering held at Novosibirsk, Russia October 2-6, 2018, pp. 518-521. 